〔Med. Entomol. Zool. Vol. 61 No. 1 p. 69-78 2010〕

\title{
Prediapause migration and overwintering of Culex tritaeniorhynchus (Diptera: Culicidae) observed in a park in urban Tokyo during 2007 to 2009
}

\author{
Yoshio TsudA ${ }^{1)}$ and Kyeong Soon $\mathrm{Kim}^{1)}{ }^{1)}$ ) \\ 1) Department of Medical Entomology, National Institute of Infectious Diseases, \\ Toyama 1-23-1, Shinjuku-ku, Tokyo 162-8640, Japan \\ 2) The United Graduate School of Veterinary Sciences, Gifu University, \\ 1-1 Yanagido, Gifu, Gifu 501-1193, Japan
}

(Received: 23 October 2009; Accepted: 24 December 2009)

\begin{abstract}
Prediapause migration of Culex tritaeniorhynchus reported one year previously was observed again in the autumn of 2008 in the same park in urban Tokyo. The time course of prediapause migration in 2007 and 2008 was similar starting in mid-/late September, peaking in mid-October and ending in December. The density of Cx. tritaeniorhynchus that migrated was higher in 2008 than 2007 throughout the study period with a peak density of 3,740 per $1 \mathrm{hr}$ of sweeping, 3.5 times higher than in 2007. A total of 16,892 and 29,188 Cx. tritaeniorhynchus resting on vegetation were collected by sweeping from April to December in 2007 and 2008, respectively, with $99.9 \%$ collected during September to December in both years. Dissection showed that $96.5 \%(222 / 230)$ of these females in 2008 were in reproductive diapause with an ovariole stage of $\mathrm{N}$ or I and a primary to secondary follicular ratio of $\leq 1.5$. In addition to $C x$. tritaeniorhynchus, 11 mosquito species were collected in this study from September to December and 6 species were breeding in the park. The remaining 3 species were rice field mosquitoes and appeared in the autumn, coinciding with the appearance of $C x$. tritaeniorhynchus. Mosquito collections were made in 2 additional study sites in mid-October 2008 to check for the occurrence and density of Cx. tritaeniorhynchus, and the average density of $C x$. tritaeniorhynchus was significantly different between study sites. Hourly changes in direction and velocity of the wind during September to October indicated that a large part of the migrating $C x$. tritaeniorhynchus originated from north to north-northwest areas of the study park. A total of 211 overwintered $C x$. tritaeniorhynchus females including 4 blood-fed females were collected at the study site during March to early May 2009, indicating the presence of hibernacula for $C x$. tritaeniorhynchus near the study site. Blood-meal identification by PCR using primers based on the cytochrome $b$ gene and the 16 S-rDNA region of vertebrate hosts showed that two blood meals were human-derived, one was cat-derived and the remaining meal showed no amplification.
\end{abstract}

Key words: prediapause migration, Culex tritaeniorhynchus, overwintering, urban area, Tokyo

\section{INTRODUCTION}

Culex tritaeniorhynchus Giles is the main vector of Japanese encephalitis virus and is widely distributed throughout Asia (Reuben et al., 1994; Endy and Nisalak,
2002; Erlanger et al., 2009). The seasonal abundance of $C x$. tritaeniorhynchus has been studied in temperate regions, including Northern China, Korea and Japan (Fukumi et al., 1975; Wada et al., 1975; Reisen et al., 1976; Mogi, 1978; Matsuzaki, 1990; Watanabe et al., 1990; Shim et al., 
1994; Takagi et al., 1995; Ming and Xue, 1996; Kim et al., 1999). The beginning of reproduction varies among local populations and populations inhabiting warm areas start to reproduce earlier than in cool areas. However, there was almost no variation in the end of the breeding season among the local populations, and reproduction ended in late September or early October with a sudden decrease in the number of females collected by light traps in an animal shed. The importance of photoperiod and temperature has been demonstrated as the primary diapauseinducing stimuli for Cx. tritaeniorhynchus (Wada et al., 1967; Oda and Wada, 1973; Reisen et al., 1976; Oda et al., 1978, 1991).

The main larval habitats of Cx. tritaeniorhynchus are rice fields. Kamimura (1968) collected 7 Culex species, 3 Anopheles species and 1 Aedes species breeding in rice fields in prefectures neighboring Tokyo, Japan. Overwintering adults of $C x$. tritaeniorhynchus, $C x$. orientalis Edwards, Cx. bitaeniorhynchus Giles and Lutzia vorax Edwards were collected in winter (Bullock et al., 1959; Wada et al., 1968; Tsuda and Kim, 2008). Reproductive diapause of female rice field mosquitoes reared under a combination of short day $(\mathrm{L}: \mathrm{D}=8: 16)$ and low temperature $\left(21^{\circ} \mathrm{C}\right)$ was observed experimentally for $C x$. bitaeniorhynchus, Lt. vorax, Cx. mimetics Noé and Cx. vagans Wiedemann (Oda et al., 1991). These rice field mosquitoes probably overwinter at the adult stage and the overwintering generation must migrate from rice fields to the overwintering sites in late September to November.

The winter biology of rice field mosquitoes has rarely been studied in Japan, except for the $C x$. pipiens group. The winter biology of the $C x$. pipiens group in Japan has been relatively well studied in the field and laboratory (Bullock et al., 1959; Shimogama and Takatsuki, 1967; Wada et al., 1968; Oda, 1968, 1971; Oda and Wada, 1972; Makiya, 1974; Makiya and Sakurai, 1975; Makiya and Taguchi, 1982; Oda et al., 1987). A large number of overwintering females of $C x$. pipiens pallens Coquillett were collected in caves from October until March in southern and central Japan (Simogama and Takatsuki, 1967; Makiya and Taguchi, 1982). The main larval habitats of Cx. pipiens pallens in urban areas are rain gutters, water catchments and earthen jars, although larvae of this species occur in rice fields.

In 2007, we encountered the sudden autumnal appearance of a large number of $C x$. tritaeniorhynchus in a park in an urban area of Tokyo and most of the females collected were found to be in reproductive diapause with examination of ovarian development (Tsuda and Kim, 2008). There had been no field evidence of the seasonal migration of $C x$. tritaeniorhynchus before our observations, and we questioned whether the observed phenomenon occurs every year. Therefore, we repeated mosquito collections in the same park and compare the results in 2008 with 2007 in this paper.

\section{Materials And Methods}

Main study site: Rinshi-no-mori Park, where the prediapause migration of a large number of $C x$. tritaeniorhynchus was observed in 2007, was selected for the present study. The park is 12 ha located in an urban area of Tokyo, Japan. Many trees, shrubs and grasses cover a large part of the park. One area in the southern part of the park (about $600 \mathrm{~m}^{2}$ ) was selected for mosquito collection. Approximately 90\% of the area was under tree canopy and the forest floor was covered with shrubs, herbs and grasses. Resting adults were found on the herbaceous plants Iris japonica, Liriope muscari and Reineckea carnea.

Additional study sites: Two additional study sites were selected and mosquitoes were collected using a sweep net to determine the occurrence and density of Cx. tritaeniorhynchus. Shizen-kyoikuen, Institute for Nature Study, a branch of the National Science Museum, Tokyo, was 
selected as one additional study site near the main study site and mosquito collections were carried out on 7 October 2008. The Institute has a vegetated area of 20 ha, located about $2 \mathrm{~km}$ northeast of the main study site, Rinshi-no-mori Park. There are various larval habitats, including ponds, streams and tree holes under the tree canopy. Seven areas with different vegetation were identified and examined by sweeping, and 31 mosquito samples collected. Another additional study site, Izumi-Shizen-koen, is 42 ha in size, located about $47 \mathrm{~km}$ east of the main study site surrounded by rice fields and secondary forest in Chiba Prefecture. Sweeping collections of mosquitoes from vegetation were carried out at Izumishizen-koen on 17 October 2008 and 34 mosquito samples were collected from 3 areas with different vegetations.

Mosquito collection and measurement: Adult mosquitoes resting on vegetation were collected two to three times a week from April to December in 2007 and 2008 with a sweep net (36 $\mathrm{cm}$ in diameter) for 1 hr after sunrise, and 112 and 138 samples were taken in 2007 and 2008, respectively. In 2008 the collection period was changed from $1 \mathrm{hr}$ to $30 \mathrm{~min}$ after 9 October because of the high density of Cx. tritaeniorhynchus. Mosquitoes were transported to the laboratory, species identified and stored at $-20^{\circ} \mathrm{C}$ for later dissection. A total of $226 C x$. tritaeniorhynchus females collected on the $4^{\text {th }}, 16^{\text {th }}$ and $31^{\text {st }}$ of October 2008 were selected at random, and dissected for parity check and examination of ovarian development. For Cx. tritaeniorhynchus collected in October 2007, a total of 1,076 females were dissected and the results reported by Tsuda and Kim (2008). Parity was checked by Detinova's tracheation method (Detinova, 1962). To determine the stages of the most advanced primary follicles, the lengths of 5 primary and secondary follicles per female were measured. The dissection methods followed Reisen et al. (1995). The length of 5 primary follicles at stage II and sec- ondary follicles were averaged per female and the follicular ratio calculated. Females with a follicular ratio $\leq 1.5$ (Reisen et al., 1995) or with primary follicles of stage N or I (Kawai, 1969; Oda and Wada, 1973; Oda et al., 1978) were considered to be in reproductive diapause.

To compare the density of migrated $C x$. tritaeniorhynchus between the main and additional study sites, mosquitoes resting on vegetation were collected by 20 sweeps of a sweep net and the average number of mosquitoes calculated. The mosquito collections were conducted on the $7^{\text {th }}, 15^{\text {th }}$ and $17^{\text {th }}$ of October 2008 in Shizenkyouiku-en, Rinshi-no-mori Park and Izumi-shizen-koen, respectively. Variations in mosquito density within the study site were analyzed by ANOVA for Shizenkyouiku-en and Izumi-shizen-koen, and the average density of $C x$. tritaeniorhynchus compared between the study sites.

Collection of overwintered Cx. tritaeniorhynchus in 2009: On 14 warm days from January to mid-March 2009, sweeping collections were made for $1 \mathrm{hr}$ in the afternoon where a large number of $C x$. tritaeniorhynchus were collected in the autumn of 2008 in Rinshi-no-mori Park. From mid-March to early May 2009, sweeping collections were made twice a day in the morning and evening on 44 days at the same location. Additionally, sweeping collections of overwintered mosquitoes at Izumi-shizen-koen were conducted for $2 \mathrm{hr}$ in the morning on 8 April 2009. At Rinshi-no-mori park, 4 half-gravid females were collected in April 2009 and blood-meal identification of the samples was carried out following Kim et al. (2009).

Meteorological data: Meteorological data were obtained from the nearest meteorological station approximately $9 \mathrm{~km}$ northeast of the study site through an online database of the Japan Meteorological Agency (//www.data.kishou.go.jp/). 


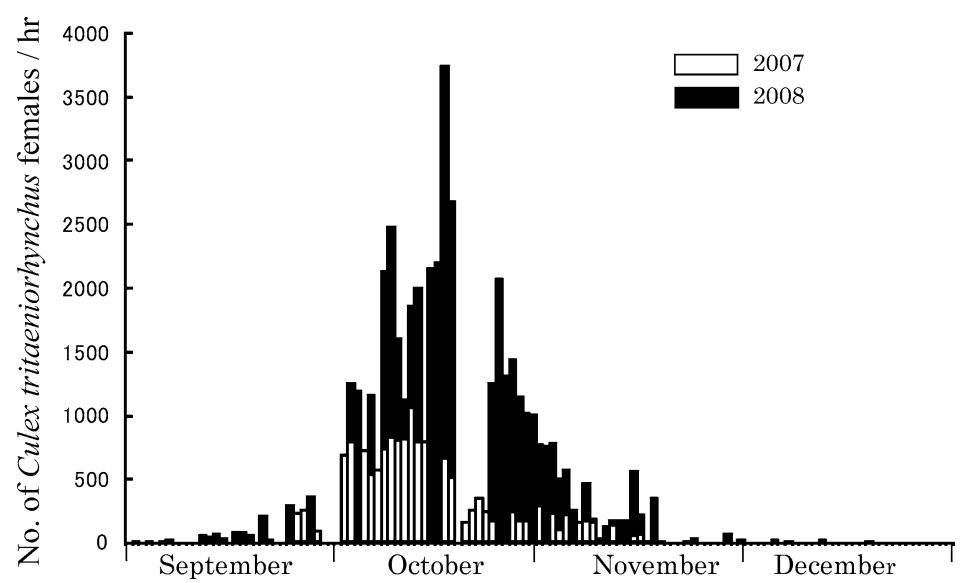

Fig. 1. Number of Cx. tritaeniorhynchus females collected per hour of sweeping from September to December in 2007 (open bars) and 2008 (closed bars).

Table 1. Summary of prediapause migration of Cx. tritaeniorhynchus, peak density of females, total number collected, parity and proportion of diapausing females observed in Rinshi-no-mori Park, Tokyo from April to December 2007 and 2008.

\begin{tabular}{llcc}
\hline \hline & & 2007 & 2008 \\
\hline Prediapause migration & Start & 26 September & 12 September \\
& Peak & 13 October & 18 October \\
& End & 8 December & 20 December \\
Peak density of females/hr & & 1,062 & 3,740 \\
Total collected & Females & 14,090 & 27,471 \\
& Males & 2,802 & 1,717 \\
Parity (\%) & & $4.4(41 / 936)$ & $2.6(6 / 230)$ \\
Diapause (\%) & & $85.7(120 / 141)$ & $96.5(222 / 230)$ \\
\hline
\end{tabular}

\section{REsults}

Prediapause migration of $\boldsymbol{C x}$. tritaeniorhynchus: Temporal changes in the density of female Cx. tritaeniorhynchus per hour collected with a sweep net during September to December in 2007 and 2008 are shown in Fig. 1, and a summary of the prediapause migration and the results of mosquito dissections are shown in Table 1 and Fig. 2. From April to December a total of 16,892 and 29,188 Cx. tritaeniorhynchus were collected by 112 and 138 mosquito collections in 2007 and 2008, respectively, and $99.9 \%$ of Cx. tritaeniorhynchus $(16,870 / 16,892$ and $29,158 / 29,188$ in 2007 and 2008, respectively) were collected during September to December (Tables 1 and 2). The time course of prediapause

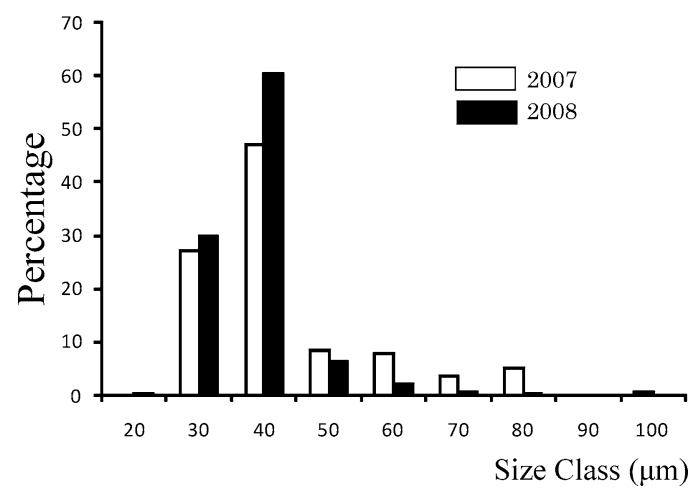

Fig. 2. Frequency distribution of the length of primary follicles observed in 2007 (open bars) and 2008 (closed bars). Follicles were divided into nine size classes at intervals of $10 \mu \mathrm{m}$.

migration in 2007 and 2008 was similar starting in mid-/late September, peaking in mid-October and ending in December. In these two years, big differences were 
Table 2. Total number of mosquitoes collected by sweeping in autumn from

September to December in 2007 and 2008 in Rinshi-no-mori Park, Tokyo, Japan.

\begin{tabular}{|c|c|c|c|c|}
\hline \multirow{2}{*}{ Species } & \multicolumn{2}{|c|}{ Year of collection } & \multirow{2}{*}{ Total } & \multirow{2}{*}{$\begin{array}{l}\text { Larval habitats in } \\
\text { the study site }\end{array}$} \\
\hline & 2007 & 2008 & & \\
\hline Cx. tritaeniorhynchus & 16,870 & 29,158 & 46,028 & Not exist \\
\hline Ae. albopictus & 2,846 & 3,370 & 6,216 & Exist \\
\hline Cx. pipiens gr. & 1,007 & 414 & 1,421 & Exist \\
\hline Cx. sasai & 485 & 322 & 807 & Exist \\
\hline Lt. vorax & 197 & 225 & 422 & Exist \\
\hline Or. anopheloides & 10 & 28 & 38 & Exist \\
\hline Cx. rubithoracis & 13 & 19 & 32 & $?$ \\
\hline$C x$. orientalis & 16 & 12 & 28 & Not exist \\
\hline Cx. bitaeniorhynchus & 6 & 2 & 8 & Not exist \\
\hline Cx. inatomii & 4 & 2 & 6 & Not exist \\
\hline An. sinensis/lesteri & 0 & 4 & 4 & Not exist \\
\hline Ar. subalbatus & 1 & 2 & 3 & Exist \\
\hline
\end{tabular}

observed in the density of females throughout the study period (Fig. 1). The density in 2008 was always higher than in 2007 and the peak density in 2008 was 3.5 times higher than in 2007 . The proportion of females collected in 2008 was 94\%, significantly higher than in 2007 (83\%, Chi-square $=1386.5, \quad p<0.001)$. The frequency distribution of the size of follicles differed significantly between 2007 and 2008 (Fig. 2, Kruskal-Wallis test, $p=$ 0.001 ), and the proportion of follicles in the size classes from 20 to 40 was $74 \%$ and $90 \%$ in 2007 and 2008, respectively. As shown in Table 1 a significantly higher proportion of diapausing females was observed in 2008 (96.5\%) than in 2007 (85.7\%, Chi-square $=15.8, p<0.001)$, whereas the difference in the proportion of parous females between 2007 and 2008 was not statistically significant (Chi-square $=1.5, p=0.221$ ).

Daily mean temperature was averaged and compared between 2007 and 2008 for early-, mid- and late-September. The average temperature $( \pm s d)$ in early September was almost the same, $26.2^{\circ} \mathrm{C} \pm 1.9$ vs. $26.9^{\circ} \mathrm{C} \pm 1.3$ in 2007 and 2008 , respectively, while slightly cooler temperatures were observed in mid- and late September $2008\left(24.8^{\circ} \mathrm{C} \pm 1.3\right.$ and $21.5^{\circ} \mathrm{C} \pm 3.4$, respectively) compared to $2007\left(25.8^{\circ} \mathrm{C} \pm 2.2\right.$ and $23.5^{\circ} \mathrm{C} \pm 3.6$, respectively). Hourly changes in the direction and velocity of wind were compared between 2007 and 2008 for 2 periods, September and October. In 2007, the main wind direction changed from southwest in September to north in October when the density of migrated mosquitoes increased. In 2008 the wind blew mainly from the north-northwest in both September and October. The average wind velocity (m/sec $\pm \mathrm{sd})$ in 2007 was $3.67 \mathrm{~m} \pm 0.61$ and $3.28 \mathrm{~m} \pm 1.35$ for mid-/ late- September and early-/mid-October, whereas in 2008, an average wind velocity of $2.54 \mathrm{~m} \pm 1.17$ and $2.41 \mathrm{~m} \pm 0.97$ was recorded, respectively.

Differences in density between study sites: The average density of Cx. tritaeniorhynchus females per 20 sweeps observed at the additional study site, Shizenkyoiku-en on 7 October 2008 ranged from 1.5 to 7.0 in 7 collection areas, but the difference between the collection areas was not statistically significant (ANOVA, $F=2.206, p=0.058$ ). At Izumi-shizen-koen, the density of $C x$. tritaeniorhynchus ranged from 6.0 to 24.9 females per 20 sweeps and the difference among 3 collection areas was significant (ANOVA, $F=10.47, p<$ 0.001). The overall average density of $C x$. tritaeniorhynchus in Shizen-kyouiku-en and Izumi-shizen-koen was $4.3 \pm 3.2(n=$ $31)$ and $15.1 \pm 12.6(n=34)$, respectively. This is significantly smaller than that ob- 


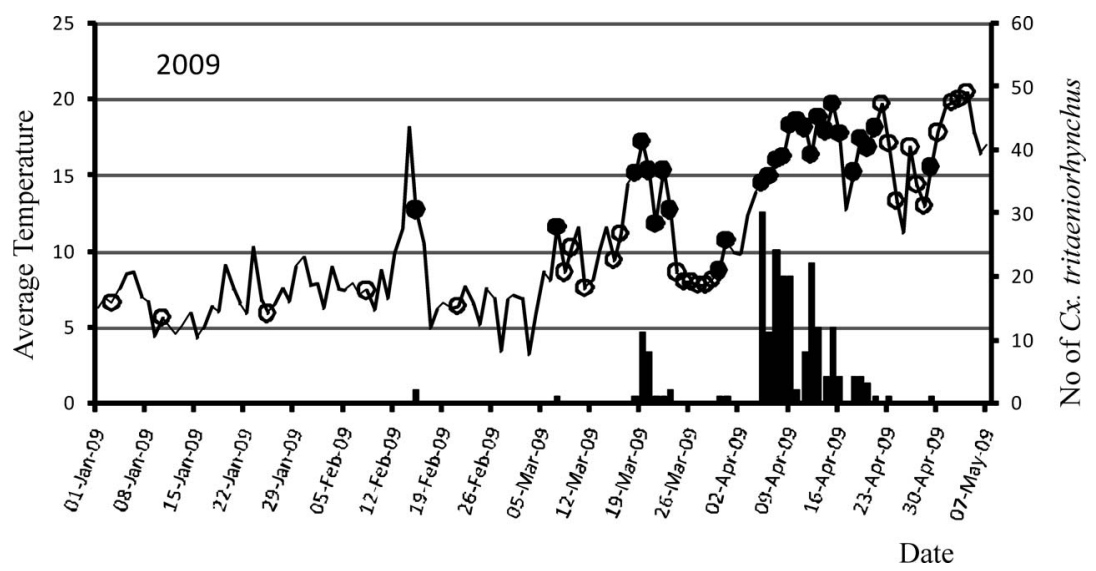

Fig. 3. Number of Cx. tritaeniorhynchus females (closed bars) collected per day in spring 2009 and daily changes in average temperature in Tokyo, Japan from January to May 2009. Closed and open circles indicate the day of mosquito collection with and without the collection of Cx. tritaeniorhynchus females, respectively.

served on 15 October 2008 in Rinshi-nomori Park (109.2 $\pm 32.2, n=5)$. The difference in the average density of Cx. tritaeniorhynchus between Shizen-kyouikuen and Izumi-shizen-koen was also significant (Tukey's HSD test, $p<0.05$ ).

Migration of rice field mosquitoes in autumn: Eleven and 12 mosquito species were encountered in autumn from September to December in 2007 and 2008, respectively (Table 2). Mosquito species with the largest numbers were $C x$. tritaeniorhynchus followed by Aedes albopictus (Skuse), Cx. pipiens group, $C x$. sasai Kano, Nitahara and Awaya, Lt. vorax, and Orthopodomyia anopheloides (Giles). Except for Cx. tritaeniorhynchus, the latter five species and Armigeres subalbatus (Coquillett) were found breeding in Rinshi-no-mori Park and larvae were collected in previous years (Tsuda unpublished). Among the remaining 6 species, Cx. orientalis, Cx. bitaeniorhynchus and An. sinensis Wiedemann/An. lesteri Baisas and $\mathrm{Hu}$ were typical rice field mosquitoes. Eleven $C x$. orientalis collected in 2008 were dissected, all were nulliparous and the proportion of females in reproductive diapause was 91\% (10/11). Larvae of Cx. rubithoracis (Leicester) and $C x$. inatomii Kamimura and Wada were never collected in Rinshi-no-mori Park in previous years (Tsuda unpublished) and adults were collected only in autumn during this study.

Appearance of overwintered $\boldsymbol{C x}$. tritaeniorhynchus: During March to May 2009, mosquitoes were collected 80 times during this study and $211 C x$. tritaeniorhynchus females and $1 C x$. orientalis female were collected. However, only 11 overwintered females of Cx. tritaeniorhynchus were collected by 42 sweeping collections from March to May in 2008 (Tsuda and Kim, 2008). Overwintered females appeared on warm days in mid-March and April when daily mean temperatures reached 15 to $20^{\circ} \mathrm{C}$ (Fig. 3). On 8 April 2009 at Izumi-shizenkoen, 12 and 1 overwintered females of $C x$. tritaeniorhynchus and $C x$. orientalis were collected, respectively, indicating the presence of overwintering sites in and near the park.

In April 2009, 4 half-gravid females of Cx. tritaeniorhynchus were collected in Rinshi-no-mori Park and blood-meal identification was performed by PCR using primers based on mitochondrial DNA cytochrome $b$ sequences and 16S-rRNA sequences of vertebrate hosts. Two blood meals were human-derived, 1 was cat- 
derived and the remaining meal showed no amplification.

\section{Discussion}

We previously reported field evidence for prediapause seasonal migration of $C x$. tritaeniorhynchus from larval habitats to overwintering sites (Tsuda and Kim, 2008). The present study indicated that the observed phenomenon takes place every year in the Kanto Plain area of Japan because the autumnal migration of a large number of $C x$. tritaeniorhynchus was observed again in this study. The time course of prediapause migration observed in 2007 and 2008 was similar, starting in mid-September, peaking in midOctober and ending in December. A similar temporal pattern of prediapause migration is reasonable because the primary stimuli inducing diapause in $C x$. tritaeniorhynchus are photoperiod and temperature (Wada et al., 1967; Oda and Wada, 1973; Reisen et al., 1976; Oda et al., 1978, 1991) and these environmental cues are regarded as the most reliable longterm cues for the regulation of insect life cycles (Tauber et al., 1986).

There was a large difference in the average density of $C x$. tritaeniorhynchus between Rinshi-no-mori Park and Shizenkyoiku-en in mid-October 2008, even though the parks are located in the same urban area within a short distance $(2 \mathrm{~km})$. The density of females migrating to Rinshi-no-mori Park continuously increased from late September to midOctober both in 2007 and 2008. The density of Cx. tritaeniorhynchus in our study site was determined simply by the balance between immigration and emigration because there are no larval habitats in the park. The continuous increase in density of mosquitoes suggests that migration takes place continuously and immigration $>$ emigration at our study site from late September to mid-October. The mosquitoes disappeared from our study site through death, including removal by sweeping, and movement. Some immigrated females die of aging, and parous females probably have a higher mortality rate than nulli-parous females. Migrated females may search for resting and overwintering sites, and when they find favorable places for resting, they tend to stay there and accumulate each day with a loss of females to death or movement to hibernacula and out of the study site. When the number of migrating females fell in late October, the balance between immigration and emigration changed and density showed a decrease until December, because death and movement continuously occurred. This may be what occurred in Rinshi-no-mori Park and Izumi-shizen-koen. On the other hand, when females fly into a certain area without suitable resting sites, they stay only for a short period and then leave the area, flying until they reach a suitable place for resting and overwintering. Shizenkyoiku-en may be unsuitable for resting and overwintering females so no accumulation of migrated females occurred. Izumi-shizen-koen is a large park with a variety of vegetation and some locations inside the park may be suitable for resting and overwintering females. As a result, migrated females accumulate at suitable locations and a significant variation in the density within the park occurred at Izumishizen-koen.

The start of migration in 2008 was about $2 \mathrm{wk}$ earlier probably because of cooler temperatures during mid- and late September. Significant differences were observed in the density, sex ratio and the proportion of diapausing females in the migrated population between 2007 and 2008. The Cx. tritaeniorhynchus population observed in this study must be a mixture of migrating populations from different rice field areas surrounding Tokyo and the annual variation in the characteristics of the migrating population may be ascribed to a different mixture of migrating populations of different origin. The average wind velocity ranged between 
3.28 and $3.67 \mathrm{~m} / \mathrm{sec}$ in 2007 and between 2.41 and $2.54 \mathrm{~m} / \mathrm{sec}$ in 2008, indicating that mosquitoes were unable to fly into the wind and flew with the wind from a north or north-northwest direction. Therefore, a large portion of the migrating population may have originated from rice field areas north or north-northwest of the study site.

We succeeded in collecting many overwintered Cx. tritaeniorhynchus in March and April 2009, suggesting that our study site is an important overwintering location for Cx. tritaeniorhynchus populations. Although we collected these females by sweeping from vegetation, the collection of 4 blood-fed mosquitoes in April indicated the increased biting activity of overwintered females. The results of blood-meal identification showed that some overwintered females readily fed on mammals they encounter inside the Rinshi-no-mori Park.

The collection of Cx. tritaeniorhynchus in autumn and early spring at Izumi-shizenkoen is also an important finding of this study because it suggests the presence of a particular habitat favorable for overwintering adult $C x$. tritaeniorhynchus in rice-field areas. The presence of overwintering sites of $C x$. tritaeniorhynchus in rice field areas has been postulated and Omori et al. (1965a) and Wada et al. (1973) concluded through experimental hibernation and field studies that the main overwintering sites of females were small underground spaces in the stone walls common in terraced rice field areas. However, many attempts in Japan have failed to collect overwintered females leaving small underground spaces in banks or stone walls by covering them with large mosquito nets (Omori et al., 1965b) or emergence traps (Buei et al., 1986). Our observations in Rinshi-no-mori Park and Izumi-shizen-koen suggest that overwintering sites of $C x$. tritaeniorhynchus are located on the forest fringe where the forest floor is covered with shrubs and perennial herbaceous plants. Additional experimental studies on the behavior of prediapausing females that migrate into these places is required to identify the exact hibernacula and to understand the overwintering ecology of Cx. tritaeniorhynchus.

The occurrence of other rice field mosquitoes, such as $C x$. orientalis, $C x$. bitaeniorhynchus and An. sinensis/lesteri, in the autumn was also observed in this study, but the numbers of mosquitoes collected were small. Ten of 11 females of $C x$. orientalis examined in this study were in reproductive diapause. Tsuda and Kim (2008) collected 3 females of Cx. orientalis together with $3 \mathrm{Cx}$. tritaeniorhynchus in April 2008 at the present study site using a dry-ice trap indicating that these females overwintered around the study site. Observations of overwintering adults of these rice field mosquitoes have been reported in previous papers. Wada et al. (1968) collected overwintering Cx. tritaeinorhynchus, $C x$. pipiens pallens, $C x$. orientalis, Cx. bitaeniorhynchus, Lt. vorax from caves during the winter in Izu Peninsula and Chiba Prefecture, Japan. Bullock et al. (1959) collected Cx. tritaeniorhynchus, Lt. vorax, Cx. rubensis Sasa and Takahashi and $C x$. hayashii Yamada from Chiba and Kanagawa Prefectures in the winter. As for overwintering $A n$. sinensis, many attempts have been made in Korea and overwintering females found in various concealed locations, such as grasses, straw piles, stone piles and other locations (Ree, 2005).

\section{ACKNOWLEDGEMENTS}

We thank Emeritus Professor Yoshito Wada, Institute of Tropical Medicine, Nagasaki University, Japan for valuable comments and suggestions. This work was partly supported by a Grant-in-Aid for Scientific Research of Emerging and Reemerging Infectious Diseases from the Ministry of Health, Labor and Welfare of the Japanese Government (H18-Shinko-009, H21Shinko-005) and Global Environmental Re- 
search Fund by Ministry of Environment Japan (S-4).

\section{REFERENCES}

Buei, K., Nakajima, S., Ito, S., Nakamura, H., Yoshida, M., Fujito, S. and Okada, N. 1986. Ecological studies on the overwintering of mosquitoes, especially Culex tritaeniorhynchus Giles in Osaka Prefecture. 1. Notes on the dry ice- and emergencetrapping in spring at terraced rice field area, 19671975. Jpn. J. Sanit. Zool., 37: 333-340. (In Japanese with English summary)

Bullock, H. R., Murdoch, W. P., Fowler, H. W. and Brazzel, H. R. 1959. Note on the overwintering of Culex tritaeniorhynchus Giles in Japan. Mosq. News, 19: 184-188.

Detinova, T. S. 1962. Age-grading methods in Diptera of medical importance. Wld. Hlth. Org. Monogr. Ser., 47: 1-216.

Endy, T. P., and Nisalak, A. 2002. Japanese encephalitis virus: ecology and epidemiology, pp. 11-48. In Mackenzie, J. S., Barrett, A. D. T. and Deubel, V. (eds.), Japanese encephalitis and West Nile viruses. Springer, New York.

Erlanger, T. E., Weiss, S., Keiser, J., Utzinger, J. and Wiedenmayer, K. 2009. Past, present, and future of Japanese encephalitis. Emerg. Inf. Dis., 15: 1-7.

Fukumi, H., Hayashi, K., Mifune, K., Shichijo, A., Matsuo, S., Omori, N., Wada, Y., Oda, T., Mogi, M. and Mori, A. 1975. Ecology of Japanese Encephalitis Virus in Japan. I. Mosquito and pig infection with the virus in relation to human incidence. Trop. Med., 17: 97-110.

Kamimura, K. 1968. The distribution and habit of medically important mosquitoes of Japan. Jpn. J. Sanit. Zool., 19: 15-34.

Kawai, S. 1969. Studies on the follicular development and feeding activity of the females of Culex tritaeinorhynchus with special reference to those in autumn. Trop. Med., 11: 145-169.

Kim, K. S., Tsuda, Y., Sasaki, T., Kobayashi, M. and Hirota, Y. 2009. Mosquito blood-meal analysis for avian malaria study in wild bird communities: laboratory verification and application to Culex sasai (Diptera: Culicidae) collected in Tokyo, Japan. Parasitol. Res., 105: 1351-1357.

Kim, H. C., Lee, K. W., Klein, T. A. and Strickman, D. A. 1999. Seasonal prevalence of mosquitoes collected from light trap in Korea (1995 1996). Korean J.
Entomol., 29: 181-187.

Makiya, K. 1974. Population dynamics of mosquitoes in Nagoya district. VII. Relationship between wing length distribution and parous rate in the overwintering Culex pipiens pallens females. Jpn. J. Sanit. Zool., 25: 229-235.

Makiya, K. and Sakurai, H. 1975. Survival of the overwintering house mosquito, Culex pipiens pallens, with special reference to the relation between wing length and survival rate. Jpn. J. Sanit. Zool., 26: 7-14.

Makiya, K. and Taguchi, I. 1982. Ecological studies on overwintering populations of Culex pipiens pallens. 3. Movement of the mosquitoes in a cave during overwintering. Jpn. J. Sanit. Zool. 33: 335343.

Matsuzaki, S. 1990. Population dynamics of Culex tritaeniorhynchus in relation to the epidemics of Japanese encephalitis in Kochi Prefecture, Japan. Jpn. J. Sanit. Zool., 41: 247-255.

Ming, J. G. and Xue, M. 1996. Progress in studies on the overwintering of the mosquito Culex tritaeniorhynchus. Southeast Asian J. Trop. Med. Public Health, 27: 810-817.

Mogi, M. 1978. Population studies on mosquitoes in the rice field area of Nagasaki, Japan especially on Culex tritaeniorhynchus. Trop. Med., 20: 173-263.

Oda, T. 1968. Studies on the follicular development and overwintering of the house mosquito, Culex pipiens pallens, in Nagasaki area. Trop. Med., 10: 195-216.

Oda, T. 1971. On the effect of the photoperiod and temperature on the feeding activity and follicular development of Culex pipiens pallens females. Trop. Med., 13: 200-204.

Oda, T., Mori, A., Eshita, Y., Uchida, K., Kurokawa, K., Suenaga, O. and Mine, M. 1991. Effect of photoperiod on follicular development of females of Culex mosquitoes. Bull. Sch. Allied Med. Sci. Nagasaki Univ., 5: 135-142.

Oda, T., Mori, A., Ueda, M., Kurokawa, K., Suenaga, O. and Zaitsu, M. 1987. Studies on imaginal diapauses in Culex pipiens complex in Japan. Bull. Sch. Allied Med. Sci. Nagasaki Univ., 1: 19-30.

Oda, T. and Wada, Y. 1972. On the development of follicles after blood-feeding in Culex pipiens pallens females which were reared under various environmental conditions. Trop. Med., 14:65-70.

Oda, T. and Wada, Y. 1973. On the gonotrophic dissociation in Culex tritaeniorhynchus summorosus 
females under various conditions. Trop. Med., 15: 189-195.

Oda, T., Wada, Y. and Mori, A. 1978. Follicular degeneration in unfed nulliparous females of Culex tritaeniorhynchus. Trop. Med., 20: 153-155.

Omori, N., Ito, S., Takenokuma, M., Mifune, K., Shichijo, A. and Hayashi, K. 1965a. Experimental hibernation of Culex tritaeniorhynchus in Nagasaki, Japan. Endem. Dis. Bull. Nagasaki Univ., 7: 288-295.

Omori, N., Wada, Y., Kawai, S., Ito, S., Oda, T., Suenaga, O. and Nishigaki, J. 1965b. Preliminary notes on the collection of hibernated females of Culex tritaeniorhynchus in Nagasaki. Endem. Dis. Bull. Nagasaki Univ. 7: 147-153.

Ree, H. I. 2005. Studies on Anopheles sinensis, the vector species of vivax malaria in Korea. Korean J. Parasit., 43: 75-92.

Reisen, W. K., Aslamkhan, M. and Basio, R. G. 1976. The effects of climatic patterns and agricultural practices on the population dynamics of Culex tritaeniorhynchus in Asia. Southeast Asian J. Trop. Med. Public Health, 7: 61-71.

Reisen, W. K., Smith, P. T. and Lothrop, H. D. 1995. Short-term reproductive diapauses by Culex tarsalis (Diptera: Culicidae) in the Coachella valley of California. J. Med. Entomol., 32: 654-662.

Reuben, R., Tewari, S. C., Hiriyan, J. and Akiyama, J. 1994. Illustrated keys to species of Culex (Culex) associated with Japanese encephalitis in Southeast Asia (Diptera: Culicidae). Mosq. Syst., 26: 75-96.

Shim, J. C., Yoon, Y. H., Cho, Y. B., Lee, J. Y., Shin, E. H., Yang, Y. C., Park, J. E., Lee, W. G., Kim, C. L. and Lee, W. J. 1994. Population density of Culex tritaeniorhynchus for surveillance of Japanese encephalitis in Korea. Rep. Natl. Inst. Health, 31: 156164.

Shimogama, M. and Takatsuki, Y. 1967. Seasonal changes in the distribution and abundance of mosquitoes especially of Culex pipiens pallens in a cave in Nagasaki City. Endem. Dis. Bull. Nagasaki Univ., 8: 159-165.
Takagi, M., Sugiyama, A. and Maruyama, K. 1995. Effect of rice culturing practices on seasonal occurrence of Culex tritaeniorhynchus (Diptera: Culicidae) immatures in three different types of rice-growing areas in central Japan. J. Med. Entomol., 32: 112118.

Tauber, M. J., Tauber, C. A. and Masaki, S. 1986. Seasonal adaptations of insects. 411 pp, Oxford University Press, New York.

Tsuda, Y. and Kim, K. S. 2008. Sudden autumnal appearance of adult Culex tritaeniorhynchus Giles (Diptera: Culicidae) at a park in urban Tokyo -First field evidence for pre-diapause migration. J. Med. Entomol., 45: 610-616.

Wada, Y., Kawai, S., Ito, S., Oda, T., Nishigaki, J., Omori, N., Hayashi, K., Mifune, K. and Shichijo, A. 1967. Ecology of vector mosquitoes of Japanese encephalitis, especially of Culex tritaeniorhynchus. 1. Results obtained in 1965. Trop. Med., 9: 45-57.

Wada, Y., Oda, T., Mogi, M., Mori, A., Omori, N., Fukumi, H., Hayashi, K., Mifune, K., Shichijo, A. and Matsuo, S. 1975. Ecology of Japanese encephalitis virus in Japan. II. The population of vector mosquitoes and the epidemic of Japanese encephalitis. Trop. Med., 17: 111-127.

Wada, Y., Oda, T., Mogi, M., Suenaga, O., Miyagi, I., Omori, N., Ito, S. and Nishigaki, J. 1973. Ecology of vector mosquitoes of Japanese encephalitis, especially of Culex tritaeiorhynchus summorosus. 5. Overwintering of Culex tritaeniorhynchus summorosus and Anopheles sinensis. Trop. Med., 15: 11-22.

Wada, Y., Miura T., Kamiya, M. and Toyokawa, K. 1968. Mosquitoes overwintering in Izu Peninsula and Mt. Nokogiri. Jpn. J. Sanit. Zool., 19: 82-83.

Watanabe, M., Arakawa, R. and Kamimura, K. 1990. Relationship between yearly change of captured numbers and insecticide resistance of Culex tritaeniorhynchus in Toyama Prefecture. Jpn. J. Sanit. Zool., 41: 59-62. 